\title{
Viral response to specifically targeted antiviral therapy for hepatitis $C$ and the implications for treatment success
}

\author{
Curtis L Cooper MD FRCPC
}

CL Cooper. Viral response to specifically targeted antiviral therapy for hepatitis $\mathrm{C}$ and the implications for treatment success. Can J Gastroenterol 2010;24(6):385-390.

Currently, hepatitis $\mathrm{C}$ virus (HCV) antiviral therapy is characterized by long duration, a multitude of side effects, difficult administration and suboptimal success; clearly, alternatives are needed. Collectively, specifically targeted antiviral therapy for HCV (STAT-C) molecules achieve rapid viral suppression and very high rapid virological response rates, and improve sustained virological response rates. The attrition rate of agents within this class has been high due to various toxicities. Regardless, several STAT-C molecules are poised to become the standard of care for HCV treatment in the foreseeable future. Optimism must be tempered with concerns related to the rapid development of drug resistance with resulting HCV rebound. Strategies including induction dosing with interferon and ribavirin, use of combination high-potency STAT-C molecules and an intensive emphasis on adherence to HCV antiviral therapy will be critical to the success of this promising advance in HCV therapy.

Key Words: Hepatitis C; Interferon; Resistance; Ribavirin; STAT-C; Treatment; Virus

$\mathrm{H}$ epatitis $\mathrm{C}$ virus (HCV) infection is widespread, with an estimated 170 to 180 million individuals infected worldwide $(1,2)$. It is a significant cause of liver disease and is the leading indication for liver transplantation $(3,4)$. Current interferonbased therapies are limited by restricted efficacy and significant adverse effects often requiring discontinuation of treatment (5), subcutaneous injection of interferon and frequent oral ribavirin dosing. There is an important unmet need for more effective, more convenient and better tolerated HCV antiviral treatments (5). The approach to treatment of HCV infection may be undergoing a shift because consideration is being given to augmenting and, perhaps someday supplanting, treatments based on interferon with agents that target HCV replication. This development has challenges that are in some ways similar to those encountered with the treatment of HIV infection - namely, HCV is a versatile virus that develops resistance to antiviral agents.

$\mathrm{HCV}$ is a positive-strand RNA virus $(3,6)$. Its genome codes for a polypeptide of approximately 3000 amino acid residues, which is further processed into individual structural (core, E1 and E2) and nonstructural (NS2, NS3, NS4A, NS4B, NS5A and NS5B) proteins by host and viral NS2 and NS3 proteases $(2,7)$. The NS proteins function as enzymes or accessory factors involved in replication. The viral replication strategy

\section{La réponse virale à une antivirothérapie ciblée spécifiquement contre l'hépatite $\mathrm{C}$ et les répercussions de la réussite du traitement}

L'antivirothérapie du virus de l'hépatite C (VHC) se caractérise par sa longue durée, sa multitude d'effets secondaires, son administration difficile et son succès sous-optimal. De toute évidence, il faut trouver d'autres solutions. Collectivement, les molécules de l'antivirothérapie ciblée spécifiquement (STAT-C) contre le VHC entrainent des taux de suppression virale rapide et de réponse virologique très rapide et améliorent le taux de réponse virologique soutenue. Le taux d'attrition des agents de cette catégorie est élevé en raison de diverses toxicités. Néanmoins, plusieurs molécules de STAT-C sont en voie de devenir la norme de soins du VHC dans un avenir prévisible. Il faut tempérer l'optimisme par les préoccupations relatives à l'apparition rapide d'une pharmacorésistance entrainant le rebond du VHC. Les stratégies, incluant des doses inductives par l'interféron et la ribavirine, le recours à une association de molécules de STAT-C de forte puissance et une mise en valeur intensive du respect de l'antivirothérapie contre le $\mathrm{VHC}$, seront essentielles à la réussite de ce progrès prometteur du traitement du VHC.

Ottawa Hospital and University of Ottawa, Ottawa, Ontario

Correspondence and reprints: Dr Curtis L Cooper, Division of Infectious Diseases, Department of Medicine, The Ottawa Hospital,

G12-501 Smyth Road, Ottawa, Ontario K1H 8L6. Telephone 613-737-8924, fax 613-737-8164, e-mail ccooper@ottawahospital.on.ca Received for publication August 6, 2009. Accepted November 12, 2009 
these agents has produced encouraging efficacy, safety and tolerability data $(2,14)$. However, emergence of viral resistance represents an obstacle to success.

The present review considers the role of STAT-C therapy in $\mathrm{HCV}$ treatment and the implications of viral resistance on STAT-C effectiveness. The discussion will be restricted to agents eliciting their effect on HCV NS enzymes.

\section{VIROLOGICAL RESPONSE TO STAT-C THERAPY}

Rapid HCV virological clearance is well-recognized as a predictor of high rates of sustained virological response (SVR) in recipients of pegylated interferon (peginterferon) and ribavirin $(15-17)$. However, only approximately $15 \%$ of genotype 1 -infected individuals achieve rapid virological response (RVR) with interferon- and ribavirin-based therapies (ie, undetectable HCV RNA after four weeks of treatment) (14). In contrast, many STAT-Cs have been identified to possess the ability to rapidly suppress HCV viremia - even as monotherapy $(4,10,18$ 20). Despite this promise, there has been a high attrition rate due to clinical toxicities (BILN-2061 [cardiotoxicity], HCV796 [hepatotoxicity], valopicitabine [gastrointestinal toxicity], R1626 [hematological toxicities]). Thankfully, development of other STAT-Cs continues.

\section{POLYMERASE INHIBITORS}

A rapid, dose-related, clinically significant antiviral response was observed with VCH-759 (a non-nucleoside inhibitor) monotherapy, which was similar for both HCV genotypes 1a and $1 \mathrm{~b}(21)$. $\mathrm{VCH}-222$, another non-nucleoside inhibitor, also achieved rapid and potent virological suppression when used as monotherapy for three days (22). Non-nucleoside HCV polymerase inhibitor PF-00868554 (filibuvir) treatment in subjects with genotype $1 \mathrm{HCV}$ infection resulted in a rapid, moderate decline in HCV RNA within $48 \mathrm{~h}$ of treatment initiation, but most subjects experienced rebound or plateaus in their HCV RNA levels (23). This observed viral rebound suggests rapid development of resistance to this particular monotherapy, consistent with a low barrier to resistance (10). PF-00868554 was safe and well tolerated at a range of doses.

\section{PROTEASE INHIBITORS}

Several NS3/4A protease inhibitors have demonstrated positive results. Boceprevir and telaprevir, which are furthest along in development, both achieved viral load suppression of between $2 \log _{10}$ and $5 \log _{10}$ as monotherapy $(24,25)$. Short-term treatment (eight days) with MK-7009 monotherapy resulted in rapid HCV RNA reductions in subjects with genotype $1 \mathrm{HCV}$ infection (26). Treatment-naive, genotype $1 \mathrm{HCV}$-infected subjects treated with BI201335 monotherapy achieved a rapid, marked reduction in HCV RNA, with $96 \%$ of subjects achieving a baseline reduction of greater than $2 \log _{10}(27)$. Both were generally well tolerated, although dose-dependent, clinically insignificant hyperbilirubinemia was reported with BI201335 due to inhibition of uridine 5 '-diphosphoglucuronosyltransferase, and a relatively high rate of gastrointestinal events were observed with MK-7009. TMC435 demonstrated virological potency and a favourable side effect profile as monotherapy over seven days, and in combination therapy for an additional 21 days (28).

\section{STAT-C COMBINATION TREATMENT WITH INTERFERONS}

Although the response to STAT-C monotherapy has generally been rapid for most agents, these compounds are associated with viral rebound within a short time, indicating the development of resistance. This observation parallels that of early HIV monotherapy and suggests that combination therapy using agents with nonoverlapping resistance profiles should be the model for HCV antiviral therapy in the future. Thus far, data indicate that the potent antiviral activity of STAT-Cs in combination with interferon-based HCV therapies convincingly improves HCV treatment outcomes (29-32).

The addition of the NS3/4A protease inhibitor telaprevir to 24- or 48-week peginterferon alpha-2a/ribavirin therapy significantly improved RVR, early viral response (EVR), SVR and reduced relapse rates in subjects with genotype $1 \mathrm{HCV}$ infection (PROVE 1) (33). EVR was defined as undetectable HCV RNA (lower than $50 \mathrm{IU} / \mathrm{mL}$ ) or a $2 \log _{10}$ or greater drop in HCV RNA at week 12. The addition of telaprevir to 48-week peginterferon alpha-2a/ribavirin therapy improved RVR, EVR and SVR rates in treatment-naive subjects with genotype $1 \mathrm{HCV}$ infection (PROVE 2 study) (29). The most successful regimen in this study included telaprevir (plus peginterferon alpha-2a/ribavirin) in an initial 12-week induction treatment period, followed by standard therapy (peginterferon alpha-2a/ribavirin) alone. The PROVE 3 study examined the addition of telaprevir to peginterferon/ribavirin regimens in subjects with genotype $1 \mathrm{HCV}$ infection who previously failed peginterferon alpha-2a/ribavirin therapy (nonresponse, partial response or relapse) $(33,34)$. The addition of telaprevir resulted in superior RVR, EVR and SVR rates as well as diminished relapse rates compared with the control arm of peginterferon alpha-2a/ribavirin. The best performing arm consisted of triple therapy for 24 weeks followed by peginterferon alpha-2a/ribavirin for an additional 24 weeks. Previous nonresponders achieved an SVR of $38 \%$, while previous relapsers achieved an SVR of $76 \%$. The durability of the STAT-C-containing treatment was demonstrated in PROVE 3 - study participants who had follow-up data remained free of HCV RNA at one year following completion of therapy. In all three studies, rash and anemia occurred with greater frequency in the telaprevir arms than in the telaprevirsparing arms.

The SPRINT-1 trial (35) assessed boceprevir in combination with peginterferon alpha- $2 \mathrm{~b}$ and ribavirin. An SVR of $75 \%$ was achieved in individuals treated for 48 weeks with four weeks of peginterferon alpha-2b plus ribavirin lead-in therapy followed by the addition of boceprevir. The SVR was $56 \%$ in those receiving four weeks lead-in and 24 additional weeks of triple therapy. Of note, null responders to a one-month lead-in phase of peginterferon alpha-2b and ribavirin still achieved an SVR of $55 \%$ following the addition of boceprevir for a total of 48 weeks (36). Anemia and three-times-daily dosing represent challenges to the use of this protease inhibitor. Other protease inhibitors, used in combination with peginterferon and ribavirin, have achieved high RVR and complete EVR rates. Several doses of MK7009 administered for 28 days with peginterferon alpha-2a and ribavirin achieved RVR rates of between $69 \%$ and $82 \%$, and complete EVR rates from $76 \%$ to $89 \%$ (37).

The nucleoside analogue R7128 combined with peginterferon alpha-2a/ribavirin was effective in reducing HCV RNA 
in treatment-naive genotype 1 -infected subjects by a mean of $5.1 \log _{10} \mathrm{IU} / \mathrm{mL}$ after 28 days of dosing $(38,39)$. High rates of RVR were reported (85\% with $1500 \mathrm{mg}$ R7128 twice daily versus $19 \%$ for placebo) and were independent of HCV subtype (1a or $1 b)$ or race. Combination treatment was well tolerated, with adverse event rates similar to rates achieved with standard care. Filibuvir, in combination with peginterferon and ribavirin, in treatment-naive, genotype 1-infected recipients achieved similar RVR rates $(80 \%$ in the $500 \mathrm{mg}$ twicedaily arm) (40).

Based on data from the SPRINT-1, PROVE 2, PROVE 3 and STEALTH-C trials, ribavirin appears to be important to the success of the STAT-C/peginterferon/ribavirin combination therapies because response rates were lower and relapse rates higher among subjects in the ribavirin-sparing arms of these trials $(29,31,33)$. A prodrug of ribavirin - taribavirin possesses similar efficacy as ribavirin, although with less anemia $(41,42)$. Use of taribavirin may enable the benefits of ribavirin to be retained without the erythrotoxicity.

\section{Nongenotype 1 infection}

Although interferon-based therapeutic efficacy differs by genotype, successful outcomes are possible for all. This level of success cannot be expected for either HCV polymerase inhibitor monotherapy or protease inhibitor monotherapy. The current clinical research approach emphasizing the treatment of genotype 1-infected participants may require reconsideration. Not only may results from these studies not be applicable to other genotypes, but compounds without effect in genotype 1 infections may be abandoned before investigating the therapeutic potential in nongenotype 1 infection. It is encouraging to note that at least some STAT-C molecules possess in vivo activity against nongenotype 1 virus. R7128, combined with peginterferon alpha-2a/ribavirin, displayed potent antiviral activity in subjects infected with genotype $2 / 3 \mathrm{HCV}$ who failed previous standard HCV treatment (43). HCV RNA was undetectable by week 4 in $90 \%$ of subjects receiving R7128; the mean decrease in HCV RNA in this group was $5.0 \log _{10} \mathrm{IU} / \mathrm{mL}$. Genotype 4 -infected recipients of combination peginterferon ribavirin plus telaprevir achieved greater virological suppression than peginterferon and ribavirin, or telaprevir monotherapy over a 15-day period (44).

\section{EVOLUTION OF RESISTANCE TO STAT-C}

Resistance to STAT-C therapy has proven to be an obstacle in the development of these agents for HCV treatment. Even in subjects who initially achieved complete HCV RNA suppression on telaprevir monotherapy (two of five naive subjects [45]), eventual breakthrough with resistant mutants was observed by 24 weeks. The error-prone nature of the RNAdependent RNA polymerase of $\mathrm{HCV}$ and the high rate of $\mathrm{HCV}$ viral production contribute to a high mutation rate, combined with the circulation of multiple different - but closely related variants (quasispecies) within one individual create conditions that are ideal for the emergence of drug resistance $(4,46)$.

\section{STAT-C resistance mutations}

Most in vitro resistance mutations in HCV NS5B RNA polymerase occur near the four sites to which current polymerase inhibitors bind (10); the nucleoside analogue resistance mutations S282T and S96T are the most common. Considerably more mutations are associated with reduced activity of nonnucleoside inhibitors, primarily in the thumb domain near the thumb and palm domain interface. Different target sites for nonnucleoside inhibitors within NS5B polymerase can be expected to produce different resistance profiles (47). In the NS3 protease domain, resistance mutations in vitro occur primarily at the R155, A156 and D168 residues $(4,10)$. In vivo data tend to be derived from relatively small clinical trials. In general, polymerase inhibitors have a higher genetic barrier for resistance than protease inhibitors in treated patients (20). However, tremendous variability within each class of molecules exists. The NS5B polymerase inhibitor resistance mutations S96T, N142T and S282T have been reported for nucleoside inhibitors, and $\mathrm{C} 316 \mathrm{Y}$ and $\mathrm{Y} 448 \mathrm{H}$ for non-nucleoside inhibitors $(4,18)$.

Several in vivo resistance mutations have been identified for the protease inhibitor boceprevir in clinical studies, including T54A, A156S/T and V170A $(4,10,18)$. A key telaprevir resistance mutation was identified at residue A156; however, additional substitutions that were not found in vitro were identified as well. High-level resistance to telaprevir is conferred with double mutants (ie, mutations at amino acid positions 36 and 155, or 36 and 156) (47,48). In study subjects who experienced viral load rebound after an initial decline, the majority of resistance mutations in telaprevir-treated subjects were V36A/M, which were low-resistance variants (10). Residue R155 mutations were the most fit resistance species in telaprevir-treated subjects. The A156S/T mutation also confers cross-resistance to boceprevir (4).

Although many viral quasispecies exist, the prevalence of detectable major resistance mutations is very low in the absence of treatment pressure (49). This observation is consistent with the principle that viruses prefer to remain in an optimally virological fit 'wild-type' form unless other factors, especially antiviral pressure, force the virus to mutate to a form that may be less fit but, nevertheless, able to survive. STAT-C resistance mutations appear to originate from the outgrowth of pre-existing resistant virus in addition to de novo response to treatment (2,5,50-52). STAT-C resistance persists at levels that vary depending on selection pressure from treatment, among other factors $(46,53)$. Viruses with resistance mutations were associated with reduced fitness (54). Mutants that arise in conserved regions across HCV genotypes are not likely to be viable (10). Furthermore, analogous to lamivudine and enfuvirtide in HIV, some resistant variants may have a fitness advantage versus wild-type virus in the presence of drugs $(5,55,56)$. The presence of resistant variants seems to result from the low-fidelity polymerase that lacks proofreading function $(53,57)$ resulting in a high error rate. This observation, together with a rapid viral turnover rate, indicates that a large population of quasispecies is present in every infected patient. These quasispecies are typically not identified by routine assays because the relative proportion of the total viral load comprising these variants is very small. With treatment, wild-type virus is inhibited, uncovering pre-existing resistant variants $(50,58)$. The initial antiviral response seen with STAT-C molecules can be attributed to a rapid reduction in wild-type virus, followed by the emergence of pre-existing and new resistant variants (47). Consistent with this model is the finding that when 
telaprevir was discontinued, wild-type $\mathrm{HCV}$ re-emerged within three to seven months $(41,52,54)$. This observation suggests that viral replicative fitness has an inverse correlation with STAT-C resistance when selective pressure from the drug is removed (41). Of note, high-level telaprevir-resistant variants were replaced more rapidly than low-level resistant variants (54).

In HIV infection, the generation of viral resistance mutations under the pressure of antiretroviral therapy leads to longterm retention of this resistance $(59,60)$. If the antiretroviral agent is removed, the virus will, in most cases, slowly revert to a wild-type form. However, if exposure to the antiretroviral agent is resumed, the previously generated mutation will rapidly return, thereby diminishing virological potency. The mechanism by which this mutation is 'catalogued' is not fully understood but is related to the fact that HIV inserts itself into host DNA, thereby resulting in long-term persistence.

$\mathrm{HCV}$, as an RNA virus, does not insert itself into host genetic material or, to our knowledge, 'catalogue' itself in any other way. This property partly explains why HCV infection can be permanently eliminated spontaneously or with antiviral therapy, whereas HIV infection cannot (60). It is plausible that once HCV viral mutations are replaced by wild-type virus following discontinuation of a STAT-C molecule, they will not recur, even if the same STAT-C molecule is reintroduced. This remains to be determined by conducting HCV antiviral rechallenge studies.

\section{RESISTANCE TO COMBINATION THERAPY WITH STAT-C}

The rapid emergence of resistance - even with short periods of STAT-C monotherapy - suggest the need for combination drug therapy with resistance profiles that do not overlap. In vitro, interferon-alpha seems to suppress the emergence of resistant mutations when added to STAT-C therapy, suggesting that its continued use in anti-HCV regimens would be beneficial solely beyond its antiviral activity $(2,52)$. Telaprevir combination therapy with peginterferon alpha-2a/ribavirin inhibited both wild-type and resistant HCV variants (47). The rapid development of resistance seen with telaprevir monotherapy was not observed with this combination (61). However, this effect does not seem to be limited to interferon. Combinations of STAT-Cs seem to suppress the emergence of resistant virus, either by decreasing viral load and thereby the mutation frequency, or by providing a higher genetic barrier to resistance because viruses resistant to a combination of agents likely require multiple mutations $(10,57)$.

In vitro, resistant variant emergence was less frequent with combination (protease inhibitor boceprevir [SCH 503034] plus polymerase inhibitor HCV-796) therapy compared with monotherapy (2). Debio 025 (an oral cyclophilin B inhibitor) inhibits the emergence of resistant variants to protease inhibitors (telaprevir, BILN 2061) and may also suppress resistant variant selection. It should be noted that the applicability of in vitro potency data for telaprevir and HCV-796 to in vivo potency has been questioned (58). In the only clinical trial of combination STAT-C therapy (62), no resistance was noted following 14 days of the nucleoside analogue R7227 and protease inhibitor R7128.

\section{IMPLICATIONS OF STAT-C RESISTANCE FOR HCV THERAPY}

In addition to improved efficacy and reduced drug resistance, the combination of STAT-Cs and standard agent therapy may have additional benefits. Protease inhibitors may have a role in restoring endogenous interferon activation (63). HCV NS3/4A protease increases interferon regulatory factor-3 (IRF-3) phosphorylation, blocking its translocation into the nucleus. IRF-3 is a key antiviral signalling molecule that functions as a transcriptional activator of interferon-beta. Therefore, NS3/4A protease inhibitors may restore IRF-3 control of HCV infection. Furthermore, in addition to inhibiting the emergence of both wild-type and drug-resistant variants (in combination with STAT-Cs) and delaying the emergence of drug resistance (ribavirin), peginterferon alpha-2a/ribavirin has been shown to be active against drug-resistant viral variants.

Drug resistance can result in a decline in replicative capacity - a beneficial outcome (64). Mutated variants with reduced viral fitness declined more rapidly than less-resistant mutants after telaprevir dosing ended. Similar to HIV therapy, however, ongoing replication in the presence of drug resistance favours the development of mutations that eventually benefit the virus. Therefore, viral suppression or elimination remain crucial to the effective treatment of HCV infection.

In animal studies, the addition of ritonavir to telaprevir or boceprevir substantially inhibited the latter's metabolism (65). The addition of ritonavir to the protease inhibitor narlaprevir (SCH 900518) allows for once-daily dosing of this particular STAT-C and represents a clear advantage in terms of ease of adherence (66). Theoretically, the improved earlier efficacy that may be possible with ritanovir-boosted protease inhibitors could also shorten treatment durations for HCV infection.

\section{Role of combination STAT-C therapy}

Combination R7128 (nucleoside analogue) plus R7227 (protease inhibitor) dosed over a maximum 14-day period in treatmentnaive recipients achieved greater than additive antiviral activity, with a mean $3.9 \log _{10} \mathrm{IU} / \mathrm{mL}$ decline in HCV RNA from baseline. No viral rebound and no adverse events requiring dose modification or discontinuation were reported (67). In vitro data, including a study (68) that found a lack of cross-drug class resistance, support the use of STAT-C combination therapy and raise the possibility of interferon-sparing regimens.

\section{Timing of STAT-C initiation and dosing duration}

The timing of STAT-C initiation is currently under evaluation. There are several potential benefits of an induction phase of peginterferon and ribavirin, followed by the subsequent addition of a STAT-C molecule. The fully therapeutic drug levels of ribavirin and interferon can be achieved. A reduction in $\mathrm{HCV}$ RNA levels, even if not to undetectable levels, may reduce the probability of producing STAT-C drug resistance. Of note, a lower proportion of subjects in the lead-in arms of SPRINT-1 had virological breakthrough (4\% to $5 \%$ ) compared with the nonlead-in arms (7\% to $11 \%$ ) (31). The likelihood of treatment success (ie, SVR) can be predicted before adding a STAT-C. For example, if an RVR was achieved at four weeks (ie, undetectable HCV RNA levels), then the addition of a STAT-C may not be necessary or the duration of all combination therapy could be reduced from the standard 48-week regimen. 
The duration of STAT-C dosing is, in large part, dictated by virological potency, durability, susceptibility to mutation and side effect profile. In the SPRINT-1 study, a greater proportion of treatment-naive subjects with genotype $1 \mathrm{HCV}$ infection treated for 44 to 48 weeks with boceprevir plus standard peginterferon alpha-2b/ribavirin therapy achieved an SVR than those treated for 24 to 28 weeks - with or without a four-week standard therapy lead-in (31). This implies that shorter duration therapy may not be the ideal objective on which to focus.

\section{CONCLUSIONS}

Alternatives to currently available HCV antiviral therapy are clearly needed. STAT-C molecules achieve rapid HCV suppression, very high RVR rates and have been demonstrated to improve SVR $(29,33)$. The attrition rate of agents within this class has been high due to various drug-specific toxicities. Nonetheless, several are poised to become standard of care $\mathrm{HCV}$ treatment in the foreseeable future. Optimism must be balanced by concerns related to the rapid development of drug resistance resulting in virological rebound and, potentially, to the loss of other same-class STAT-C molecules as treatment options despite never being exposed. Strategies including predosing with interferon and ribavirin, use of combination highpotency STAT-C molecules and an intensive emphasis on complete adherence to $\mathrm{HCV}$ antiviral therapy will be critical to the success of this promising advance in HCV therapy.

ACKNOWLEDGEMENTS/DISCLOSURE: The author acknowledges Ursula Jorch of Jorch Consulting Inc for assistance in manuscript preparation, financial support of which was provided by Hoffmann-La Roche Ltd.

\section{REFERENCES}

1. Baldo V, Baldovin T, Trivello R, Floreani A. Epidemiology of HCV infection. Curr Pharm Des 2008;14:1646-54.

2. Parfieniuk A, Jaroszewicz J, Flisiak R. Specifically targeted antiviral therapy for hepatitis C virus. World J Gastroenterol 2007;13:5673-81.

3. Beaulieu PL. Non-nucleoside inhibitors of the HCV NS5B polymerase: Progress in the discovery and development of novel agents for the treatment of HCV infections. Curr Opin Investig Drugs 2007;8:614-34.

4. McGovern BH, Abu Dayyeh BK, Chung RT. Avoiding therapeutic pitfalls: The rational use of specifically targeted agents against hepatitis C infection. Hepatology 2008;48:1700-12.

5. Stauber RE, Kessler HH. Drugs in development for hepatitis C. Drugs 2008;68:1347-59.

6. Glenn JS. Molecular virology of the hepatitis $C$ virus: Implication for novel therapies. Infect Dis Clin North Am 2006;20:81-98.

7. Rice C. Flaviviridae: The viruses and their applications. In: Fields B, Knipe D, Howley P, eds. Fields Virology, Philadelphia: Lippincott-Raven Publishers, 1996:931-60.

8. Bartenschlager R. Hepatitis C virus replicons: Potential role for drug development. Nat Rev Drug Discov 2002;1:911-6.

9. De Francesco R, Tomei L, Altamura S, Summa V, Migliaccio G. Approaching a new era for hepatitis $C$ virus therapy: Inhibitors of the NS3-4A serine protease and the NS5B RNA-dependent RNA polymerase. Antiviral Res 2003;58:1-16.

10. Koev G, Kati W. The emerging field of HCV drug resistance. Expert Opin Investig Drugs 2008;17:303-19.

11. Kolykhalov AA, Mihalik K, Feinstone SM, Rice CM. Hepatitis C virus-encoded enzymatic activities and conserved RNA elements in the 3 ' nontranslated region are essential for virus replication in vivo. J Virol 2000;74:2046-51.

12. Lohmann V, Körner F, Koch J, Herian U, Theilmann L, Bartenschlager R. Replication of subgenomic hepatitis $\mathrm{C}$ virus RNAs in a hepatoma cell line. Science 1999;285:110-3.
13. Lesburg CA, Cable MB, Ferrari E, Hong Z, Mannarino AF, Weber PC. Crystal structure of the RNA-dependent RNA polymerase from hepatitis $C$ virus reveals a fully encircled active site. Nat Struct Biol 1999;6:937-43.

14. McHutchison JG, Lawitz EJ, Shiffman ML, et al; IDEAL Study Team. Peginterferon alfa-2b or alfa-2a with ribavirin for treatment of hepatitis C infection. N Engl J Med 2009;361:580-93.

15. Ferenci P, Fried MW, Shiffman ML, et al. Predicting sustained virological responses in chronic hepatitis $\mathrm{C}$ patients treated with peginterferon alfa-2a (40 KD)/ribavirin. J Hepatol 2005;43:425-33.

16. Jensen DM, Morgan TR, Marcellin P, et al. Early identification of HCV genotype 1 patients responding to 24 weeks peginterferon alpha-2a (40 kd)/ribavirin therapy. Hepatology 2006;43:954-60.

17. Zeuzem S, Buti M, Ferenci P, et al. Efficacy of 24 weeks treatment with peginterferon alfa- $2 \mathrm{~b}$ plus ribavirin in patients with chronic hepatitis $\mathrm{C}$ infected with genotype 1 and low pretreatment viremia. J Hepatol 2006;44:97-103.

18. Liu-Young G, Kozal MJ. Hepatitis C protease and polymerase inhibitors in development. AIDS Patient Care STDS 2008;22:449-57.

19. Sheldon J, Barreiro P, Vincent V. Novel protease and polymerase inhibitors for the treatment of hepatitis $\mathrm{C}$ virus infection. Expert Opin Investig Drugs 2007;16:1171-81.

20. Soriano V, Madejon A, Vispo E, et al. Emerging drugs for hepatitis C. Expert Opin Emerg Drugs 2008;13:1-19.

21. Cooper C, et al. Safety, tolerability and pharmacokinetics of the $\mathrm{HCV}$ polymerase inhibitor $\mathrm{VCH}-222$ following single dose administration in healthy volunteers and antiviral activity in HCV-infected individuals. [940]. The 44th Annual Meeting of the European Association for the Study of the Liver. Copenhagen, April 22 to 26, 2009.

22. Cooper C, Lawitz EJ, Ghali P, et al. Evaluation of VCH-759 monotherapy in hepatitis C infection. J Hepatol 2009;51:39-46.

23. Hammond J, et al. Antiviral activity of the HCV polymerase inhibitor PF-00868554 administered as monotherapy in HCV genotype 1 infected subjects. [LB11]. The 59th Annual Meeting of the American Association for the Study of Liver Diseases. San Francisco, October 31 to November 4, 2008.

24. Zeuzem S, et al. Anti-viral activity of SCH 503034, a HCV protease inhibitor, administered as monotherapy in Hepatitis $\mathrm{C}$ genotype-1 (HCV-1) patients refractory to pegylated interferon (PEG-IFN-Alpha). [Hepatology 94]. The 56th Annual Meeting of the American Association for the Study of Liver Diseases. San Francisco, November 11 to 15, 2005

25. Reesink H, et al. Final results of a phase 1B, multiple-dose study of VX-950, a Hepatitis C virus protease inhibitor. [Hepatology 96]. The 56th Annual Meeting of the American Association for the Study of Liver Diseases. San Francisco, November 11 to 15, 2005.

26. Lawitz E, et al. Safety, tolerability and antiviral activity of MK-7009, a novel inhibitor of the hepatitis C virus NS3/4A protease, in patients with chronic HCV genotype 1 infection. [211]. The 59th Annual Meeting of the American Association for the Study of Liver Diseases. San Francisco, October 31 to November 4, 2008.

27. Manns M, et al. Safety and efficacy of BI201335, a new HCV NS3 protease inhibitor, in treatment-naïve patients with chronic hepatitis $\mathrm{C}$ genotype-1 infection given as monotherapy and in combination with peginterferon alfa $2 \mathrm{a}(\mathrm{P})$ and ribavirin $(\mathrm{R})$. [1849]. The 59th Annual Meeting of the American Association for the Study of Liver Diseases. San Francisco, October 31 to November 4, 2008.

28. Manns M, et al. OPERA-1 trial: Interim analysis of safety and antiviral activity of TMC435 in treatment-naïve genotype $1 \mathrm{HCV}$ patients. [11]. The 44th Annual Meeting of the European Association for the Study of the Liver. Copenhagen, April 22 to 26, 2009.

29. Hezode C, Forestier N, Dusheiko G, et al. Telaprevir and peginterferon with or without ribavirin for chronic HCV infection. N Engl J Med 2009;360:1839-50.

30. Jacobson I, et al. Interim analysis results from a Phase 2 study of telaprevir with peginterferon alfa-2a and ribavirin in treatment-naïve subjects with hepatitis C. Hepatology 2007;46:1.

31. Kwo $\mathrm{P}$, et al. Boceprevir plus peginterferon alfa-2b/ribavirin for treatment of genotype 1 chronic hepatitis $\mathrm{C}$ in previously untreated patients: Interim results from the HCV SPRINT-1 study. [LB16]. The 59th Annual Meeting of the American Association for the Study of Liver Diseases. San Francisco, October 31 to November 4, 2008. 
32. Pockros $P$, et al. Robust synergistic antiviral effect of R1626 in combination with peginterferon alfa-2a $(40 \mathrm{kD})$ with or without ribavirin - interim analysis results of Phase 2a study. [167]. The 58th Annual Meeting of the American Association for the Study of Liver Diseases. Boston, November 2 to 6, 2007.

33. McHutchison JG, Everson GT, Gordon SC, et al. Telaprevir with peginterferon and ribavirin for chronic HCV genotype 1 infection. N Engl J Med 2009;360:1827-38.

34. McHutchison J, et al. PROVE3 final results and 1 year durability of SVR with Telaprevir-based regimen in Hepatitis C genotype 1 -infected patients with prior non-response, viral breakthrough or relapse to Peginterferon-alfa-2a/b and Ribavirin therapy. [Hepatology 66]. The 60th Annual Meeting of the American Association for the Study of Liver Diseases. Boston, October 30 to November 3, 2009.

35. Kwo P, et al. HCV SPRINT-1: Final results SVR 24 Boceprevir plus PegIFN Alpha-2b/Ribavirin HCV 1 Treatment Naive Patients [4]. The 44th Annual Meeting fo the European Association for the Study of the Liver. Copenhagen, April 22 to 26, 2009.

36. Kwo $\mathrm{P}$, et al. High sustained virologic response (SVR) in genotype 1 (G1) null responders to peg-interferon alfa-2B (P) plus ribavirin (R) when treated with boceprevir (BOC) combination therapy. [Hepatology 62]. The 60th Annual Meeting of the American Association for the Study of Liver Diseases. Boston, October 30 to November 3, 2009.

37. Manns M, et al. Early viral response (EVR) rates in treatment naive patients with chronic Hepatitis C (CHC) genotype 1 infection treated with MK-7009, a novel NS3/4A protease inhibitor, in combination with pegylated interferon alfa-2A and ribavirin for 28 days. [Hepatology 63]. The 60th Annual meeting of the American Association for the Study of Liver Diseases. Boston, October 30 to November 3, 2009.

38. Lalezari J, et al. Potent antiviral activity of the HCV nucleoside polymerase inhibitor R7128 with PEG-IFN and ribavirin: Interim results of R7128 $500 \mathrm{mg}$ bid for 28 days. [66]. The 43rd Annual Meeting of the European Association for the Study of the Liver. Milan, April 23 to 27, 2008.

39. Rodriguez-Torres M, et al. Potent antiviral response to the HCV nucleoside polymerase inhibitor R7128 for 28 days with peg-IFN and ribavirin: subanalysis by race/ethnicity, weight, and HCV genotype. [1899]. The 59th Annual Meeting of the American Association for the Study of Liver Diseases. San Francisco, October 31 to November 4, 2008.

40. Jacobson I, et al. Antiviral activity of filibuvir in combination with pegylated interferon alfa-2a and ribavirin for 28 days in treatment naïve patients chronically infected with HCV genotype 1 . [Poster 1052]. The 44th Annual Meeting of the European Association for the Study of the Liver. Copenhagen, Denmark. April 22 to 26, 2009.

41. Harrison SA. Small molecule and novel treatments for chronic hepatitis C virus infection. Am J Gastroenterol 2007;102:2332-8.

42. Poordad F, et al. Sustained virologic response (SVR) results for weight-based Taribavirin versus weight-based Ribavirin in naive, chronic Hepatitis C, genotype 1 patients. [Hepatology 65]. The 60th Annual Meeting of the American Association for the Study of Liver Diseases. 2009. Boston, October 31 to November 3, 2009.

43. Gane E, et al. Antiviral activity of the HCV nucleoside polymerase inhibitor R7128 in HCV genotype 2 and 3 prior non-responders: Results of R7128 $1500 \mathrm{mg}$ BID with PEG-IFN and ribavirin for 28 days. [LB10]. The 59th Annual Meeting of the American Association for the Study of Liver Diseases. San Francisco, October 31 to November 4, 2008.

44. Benhamou Y, et al. Results of a proof of concept study (C210) of telaprevir monotherapy and in combination with peginterferon alfa2a and ribavirin in treatment-naïve genotype $4 \mathrm{HCV}$ patients. [10]. The 44th Annual Meeting of the European Association for the Study of the Liver. Copenhagen, April 22 to 26, 2009.

45. Ozeki I. Safety and antiviral activity of a monotherapy with MP-424 for 24 weeks in naïve patients with chronic hepatitis C virus genotype $1 \mathrm{~b}$ infection. [963]. The 44th Annual Meeting of the European Association for the Study of the Liver. Copenhagen, April 22 to 26, 2009.

46. Kim AY, Timm J. Resistance mechanisms in HCV: From evolution to intervention. Expert Rev Anti Infect Ther 2008;6:463-78.

47. Kronenberger B, Welsch C, Forestier N, Zeuzem S. Novel hepatitis C drugs in current trials. Clin Liver Dis 2008;12:529-55, viii.

48. Wohnsland A, Hofmann WP, Sarrazin C. Viral determinants of resistance to treatment in patients with hepatitis $\mathrm{C}$. Clin Microbiol Rev 2007;20:23-38.
49. Lopez-Labrador FX, Moya A, Gonzalez-Candelas F. Mapping natural polymorphisms of hepatitis $\mathrm{C}$ virus NS3/4A protease and antiviral resistance to inhibitors in worldwide isolates. Antivir Ther 2008;13:481-94.

50. Kieffer TL, Sarrazin C, Miller JS, et al. Telaprevir and pegylated interferon-alpha-2a inhibit wild-type and resistant genotype 1 hepatitis C virus replication in patients. Hepatology 2007;46:631-9.

51. McCown MF, Rajyaguru S, Le Pogam S, et al. The hepatitis $C$ virus replicon presents a higher barrier to resistance to nucleoside analogs than to nonnucleoside polymerase or protease inhibitors. Antimicrob Agents Chemother 2008;52:1604-12.

52. Zhou Y, Bartels DJ, Hanzelka BL, et al. Phenotypic characterization of resistant Val36 variants of hepatitis $\mathrm{C}$ virus NS3-4A serine protease. Antimicrob Agents Chemother 2008;52:110-20.

53. Timm J, Roggendorf M. Sequence diversity of hepatitis C virus: Implications for immune control and therapy. World J Gastroenterol 2007;13:4808-17.

54. Sarrazin C, Kieffer TL, Bartels D, et al. Dynamic hepatitis C virus genotypic and phenotypic changes in patients treated with the protease inhibitor telaprevir. Gastroenterology 2007;132:1767-77.

55. Deeks SG, Hoh R, Neilands TB, et al. Interruption of treatment with individual therapeutic drug classes in adults with multidrugresistant HIV-1 infection. J Infect Dis 2005;192:1537-44.

56. Deeks SG, Lu J, Hoh R, et al. Interruption of enfuvirtide in HIV-1 infected adults with incomplete viral suppression on an enfuvirtide-based regimen. J Infect Dis 2007;195:387-91.

57. Mathy JE, Ma S, Compton T, Lin K. Combinations of cyclophilin inhibitor NIM811 with hepatitis C Virus NS3-4A Protease or NS5B polymerase inhibitors enhance antiviral activity and suppress the emergence of resistance. Antimicrob Agents Chemother 2008;52:3267-75.

58. Kwong AD, McNair L, Jacobson I, George S. Recent progress in the development of selected hepatitis $\mathrm{C}$ virus NS3.4A protease and NS5B polymerase inhibitors. Curr Opin Pharmacol 2008;8:522-31.

59. Delobel P, Sandres-Sauné K, Cazabat M, et al. Persistence of distinct HIV-1 populations in blood monocytes and naive and memory CD4 T cells during prolonged suppressive HAART. AIDS 2005;19:1739-50.

60. Nottet HS, van Dijk SJ, Fanoy EB, et al. HIV-1 can persist in aged memory $\mathrm{CD}^{+} \mathrm{T}$ lymphocytes with minimal signs of evolution after 8.3 years of effective highly active antiretroviral therapy. J Acquir Immune Defic Syndr 2009;50:345-53.

61. Koch U, Narjes F. Recent progress in the development of inhibitors of the hepatitis $\mathrm{C}$ virus RNA-dependent RNA polymerase. Curr Top Med Chem 2007;7:1302-29.

62. Gane E, et al. Combination therapy with a nucleoside polymerase (R7128) and protease (R7227/ITMN-191) inhibitor in HCV: Safety, pharmacokinetics and virologic results from INFORM-1 [Hepatology 193]. The 60th Annual meeting of the American Association for the Study of Liver Diseases. Boston, October 30 to November 3, 2009.

63. Foy E, Li K, Wang C, et al. Regulation of interferon regulatory factor-3 by the hepatitis C virus serine protease. Science 2003;300:1145-8.

64. Le Pogam S, Kang H, Harris SF, et al. Selection and characterization of replicon variants dually resistant to thumb-and palm-binding nonnucleoside polymerase inhibitors of the hepatitis C virus. J Virol 2006;80:6146-54.

65. Kempf DJ, Marsh KC, Kumar G, et al. Pharmacokinetic enhancement of inhibitors of the human immunodeficiency virus protease by coadministration with ritonavir. Antimicrob Agents Chemother 1997;41:654-60.

66. Vierling J, et al. Once Daily Narlaprevir (SCH 900518) in combination with Pegintron (Peginterferon Alfa-2B) / Ribavirin for treatment-naive subjects with genotype-1 CHC: Interim results from NEXT-1, a phase 2A study. [Hepatology]. The 60th Annual Meeting of the American Association for the Study of Liver Diseases. Boston, October 31 to November 3, 2009.

67. Gane E, et al. First-in-man demonstration of potent antiviral activity with a nucleoside polymerase (R7128) and protease (R7227/ITMN-191) inhibitor combination in HCV: safety, pharmacokinetics, and virologic results from INFORM-1. [1046]. The 44th Annual Meeting of the European Association for the Study of the Liver. Copenhagen, April 22 to 26, 2009.

68. Grunberger C, Wyles DL, Kaihara KA, Schooley RT. 3-drug synergistic interactions of small molecular inhibitors of hepatitis $\mathrm{C}$ virus replication. J Infect Dis 2008;197:42-5. 


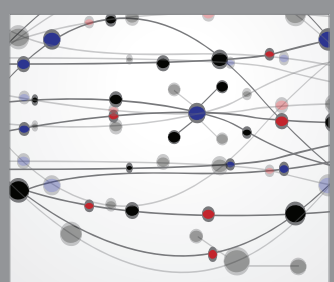

The Scientific World Journal
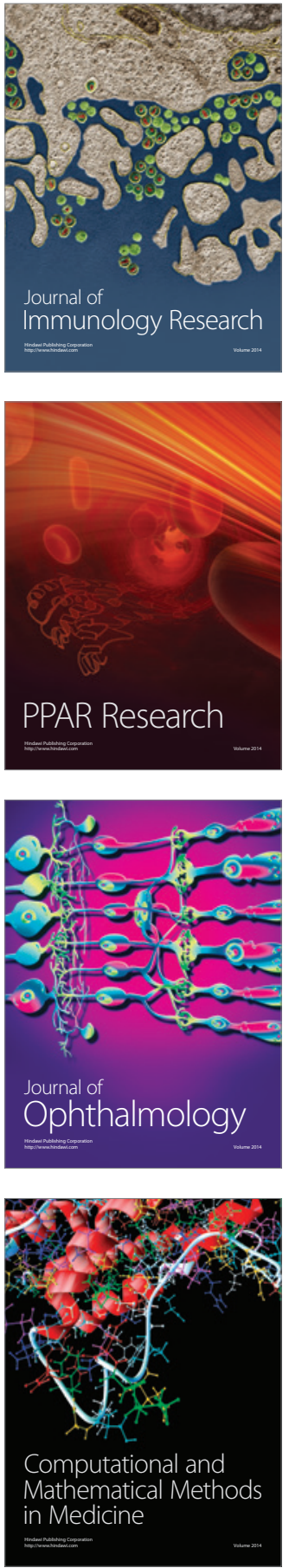

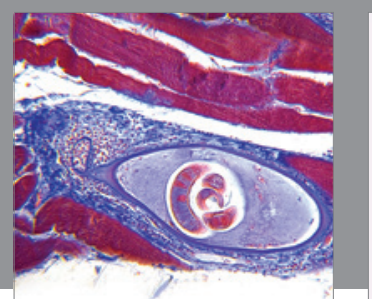

Gastroenterology Research and Practice

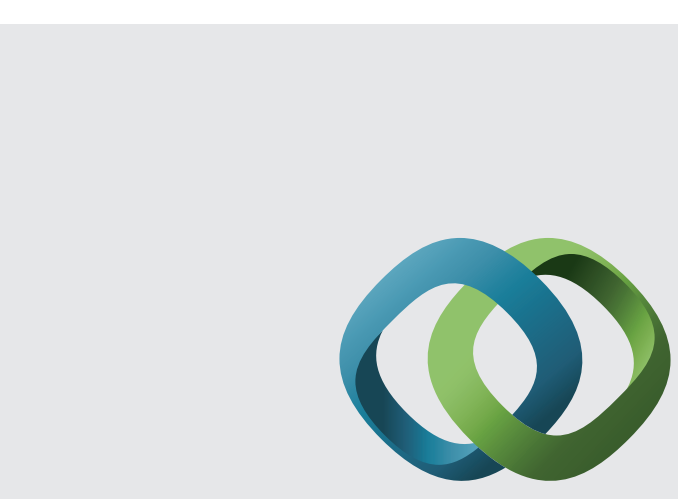

\section{Hindawi}

Submit your manuscripts at

http://www.hindawi.com
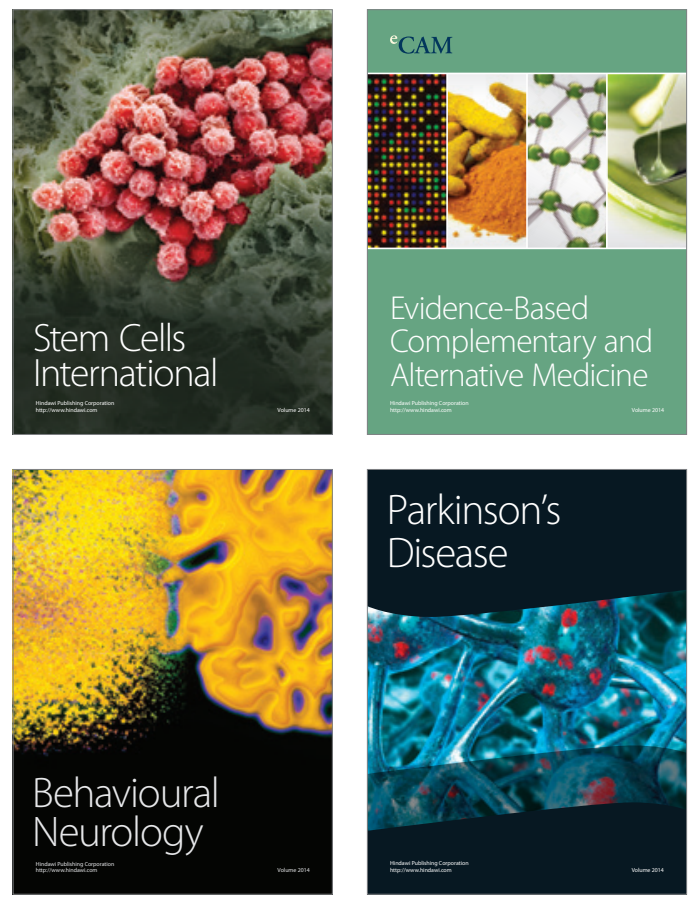
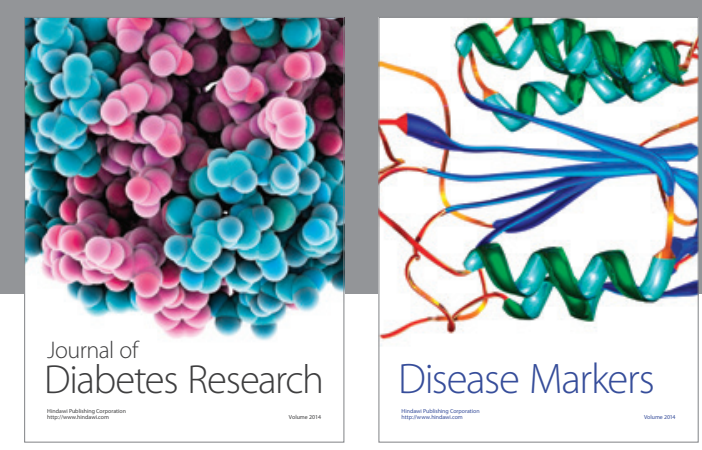

Disease Markers
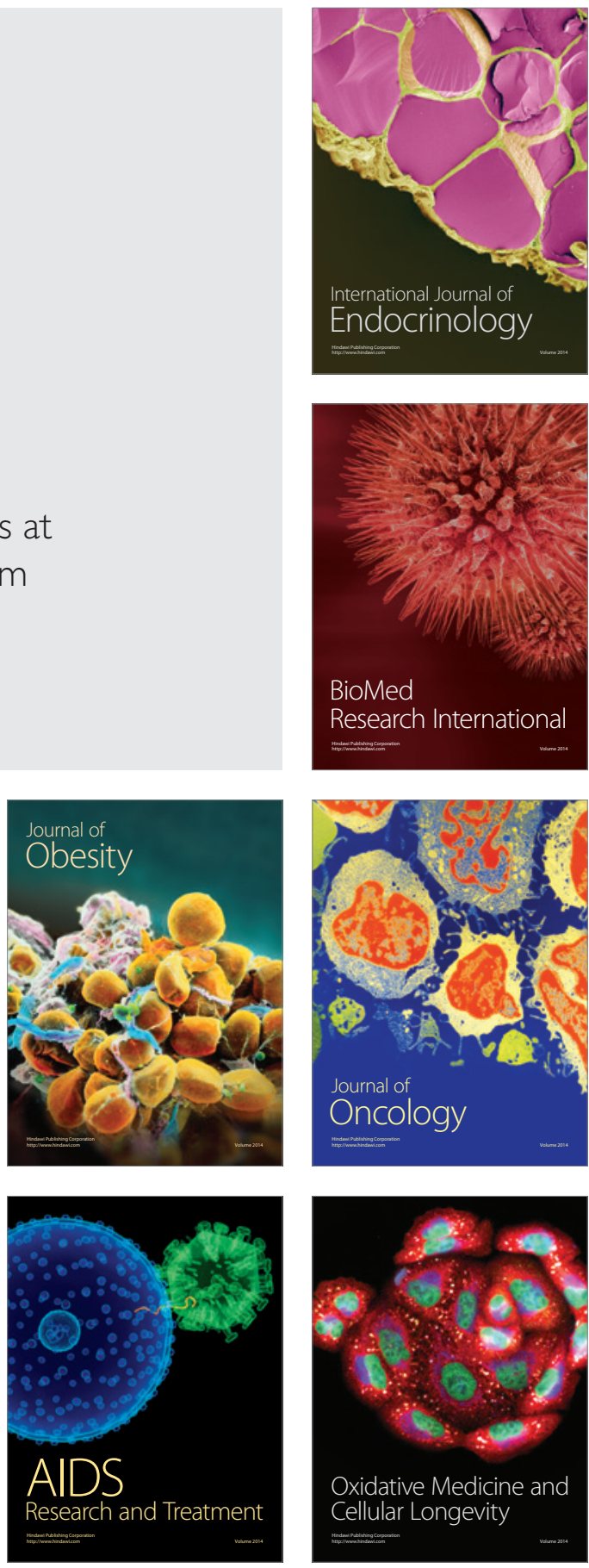